in New South Wales. I went to Perth, Brisbane and Adelaide to look at their facilities which, on the whole, weren't very good, nothing like Victoria. I well remember once visiting Toowoomba Hospital outside Brisbane. I was presented with a series of obscure inherited neurological disorders and expected to pronounce on them. None were worked up but they all had gross physical signs. It was quite interesting. But I didn't get much time to visit other places, I was so busy in Sydney.

BMB Would you like to say something about the development of psychiatry during the later part of your stay and since you have been away?

WHT This has been considerable. Apart from the improvement in the psychiatric facilities there has been a large development of academic psychiatry. When I went to Sydney I was the only Professor in Australia, a pretty daunting prospect. But now there are Chairs and Departments in Brisbane, two in Sydney, Sydney University and the University of New South Wales, Newcastle; Victoria-that was the next development after my Chair-at the University of Melbourne and Monash, in South Australia in Adelaide, and Flinders, at Perth and in Tasmania. Newcastle has appointed the first woman Professor of Psychiatry. The Australia and New Zealand College of Psychiatrists has become a very thriving organization.

BMB What do you think of their membership exam? Ours is compared adversely with theirs.

WHT This is because of misunderstanding. Private practice is much more advanced in Australia than here. Obtaining the Membership of the Royal Australian and New Zealand College of Psychiatrists shows that you are of consultant standard, it is a hallmark. Here the Membership of the Royal College of Psychiatrists only qualifies the successful candidate for further training as a senior registrar. The Australians found this difficult to understand and complained about the relatively lower standard of our Membership without realizing that it is no more than a ticket for further training. Here, but not in Australia, there is a further test, for to become a consultant psychiatrist, you have to obtain a National Health Service appointment in competition.

BMB There are features of their examination which are good, aren't there?

WHT It is more searching, more in accord with the American Boards. I was the first Senior Censor of the Royal Australian New College of Psychiatrists, but never conducted an examination. The failure rate was high and caused discontent.

BMB Is the divide between the Royal Australasian College of Physicians and the Psychiatrists' College a big one?

WHT I don't think so. They maintain friendly relations. There are senior Australian and New Zealand psychiatrists who are Members and Fellows of both. I am a Fellow of both Colleges although I didn't take any examinations.

\section{REFERENCES}

'Yellowlees, H. (1932) Clinical Lectures on Psychological Medicine. London: J. and A. Churchill.

2Stafford Clark, D. (1952) Psychiatry Today. London: Penguin.

${ }^{3}$ TrethowaN, W. H. \& CoBB, S. (1952) Neuropsychiatric aspects of Cushing's syndrome. A.M.A. Archives of Neurology and Psychiatry, 67, 283-309.

‘Stoller, A. \& ARscotr, K. W. (1955) Mental Health Facilities and Needs of Australia. Canberra.

(To be continued next month)

\title{
Tribunal Nouveau 1983: A First Taste of the Mental Health Act
}

\author{
ANNE FARMER, Senior Registrar, Springfield Hospital, London SW17
}

While not claiming any record, the Tribunal held on 4 November 1983 at Springfield Hospital to hear an appeal against detention under Section 2 of the 1983 Mental Health Act must have been among the first. The case is instructive as it illustrates the difficulties which may arise in obtaining the full facts for presentation in the short time which is available under the new legislation.

The case report

A 68-year-old single woman, a retired legal secretary, was transferred to the psychiatric hospital on 20 October after spending three weeks on a medical ward for treatment of congestive cardiac failure. She had been placed on Section 2 by the liaison psychiatric team who assessed her on the medical ward and judged her suffering from a psychotic illness and dangerous to herself and others. She demanded to go home and declined any help from medical or social services. She was informed of her rights under the Act and duly exercised them. At a preliminary hearing her appeal against detention was rejected by the District Managers.

One of the main reasons why she was considered dangerous was her method of cooking on an open fire. She 
soaked strips of cardboard in cooking oil and lit them in the grate. She would then add two pounds of sugar to get the blaze going. At the time of her admission there had been a fire in her house which occurred after she had been winded in a fall. She had not been able to respond fast enough when a lighted piece of cardboard fell on to the hearth rug and set it alight. After summoning the fire brigade she claimed that some ambulance men arrived and took her unwillingly to Casualty.

She had cooked this way ever since her electricity had been disconnected for non-payment. She owed $£ 1,000$. but she claimed that this was a false debt as the Crown Office owed her money. She believed that she was closely related to Royalty, and that her affairs were managed by a distinguished Army General, none of which was substantiated. Ever since the General had been injured in a car bombing, there had been problems over her pension and although she complained to the Crown Office, she was still waiting for the matter to be resolved. Despite her complex delusional system she managed to live as a recluse in the community without coming to the attention of the psychiatric services. She did not have a GP. Her only previous admission had been in 1980 to a general medical ward under Section 47 of the National Assistance Act, suffering from malnutrition and hypothermia.

Social reports described the condition of her house prior to admission to the psychiatric ward as 'deplorable'. There was considerable damage due to the fire. Social Services hoped to persuade the electricity board to reconnect her supply and they considered that once the electricity was available she would cook in a more conventional manner.

She presented as a pale, untidy woman with dyed green hair and a haughty manner. She had a squeaky, high pitched voice and physical examination on admission to the psychiatric ward revealed no evidence of congestive cardiac failure. Although deluded and lacking insight she had no formal thought disorder or hallucinations. Her mental state had remained unchanged throughout her stay in hospital and she refused psychotropic medication. She gave a good account of herself in both hearings and did not agree that her method of cooking constituted any fire risk.

\section{The decision}

The Tribunal decided that the fire occurred due to lack of attention when she was physically unwell. Since she had received treatment for this she was no longer a danger to herself or others and should no longer be detained against her will. They hoped, however, that she would remain as an informal patient. This she did for three days until her keys were obtained from Social Services. She then left hospital, refusing to take even the medication for her heart condition.

\section{Lessons to learn}

What can be learned from this case? Firstly, application of the Mental Health Act (1983) might have been inappropriate. Undoubtedly her delusional system interfered with her ability to seek help from the appropriate sources over her pension payments and in dealing with the electricity board. Her eccentric cooking arrangements had not proved dangerous before she became physically ill. Perhaps it would have been more appropriate to apply the National Assistance Act as had been done before.

Secondly, as patients must appeal against Section 2 within fourteen days of detention, the hearing was held at short notice. Information gathering by both medical and Social Services teams was incomplete, and we were not even sure whether the name she gave was correct or whether she had any family. The social worker was not available for either meeting and an update of the condition of the patient's home and the repairs carried out by the time of the Tribunal was not available. The possibility that she obtained her release due to inadequate presentation must be considered. However, as the number of appeals against detention under Section 2 of the new Act increases, and since hospital managers have a duty to respond quickly in setting up tribunals, key workers and consultant medical staff may frequently be unavailable. Delegation to junior members of the medical team may be a solution which is often resorted to, with the presentation skills required deemed a necessary acquisition in higher training.

Lastly, the case illustrates the difficulties inherent in assuming that Section 2 of the 1983 Act can be applied to the same patients who would have been detained under Section 25 of the 1959 Act. This case illustrates that such assumptions cannot be made. Those whose symptoms allow them to appeal will be detained less frequently and they may not obtain the observation and treatment they require. Patients whose psychopathology includes disordered thinking will be less able to use the appeal procedures. It may also mean that doctors will tend to 'play safe' in some cases and not invoke Section 2 so as not to risk hasty and inadequate presentation at a Tribunal. On the other hand, if forced to place a patient on a section, some may feel that they might as well be 'hung for a sheep as a lamb' and opt for Section 3, which allows detention for six months and appeals may be prepared for at a more leisurely pace. It therefore seems possible that changes in the Act aimed to increase the rights of the individual may in practice have the opposite effect. Some patients without insight, for whom brief compulsory admission is appropriate, may be denied this right, while others whose condition forces their psychiatrist into recommending compulsory detention may be placed on a relatively long-term order which is not, strictly speaking, in their best interests. 